\title{
Olivier Reboul, La Philosophie de l'éducation
}

PUF, « Que Sais-Je ? » 9e édition, Paris, 1989, 127 p.

\section{Alain Kimmel}

\section{OpenEdition}

\section{Journals}

Édition électronique

URL : https://journals.openedition.org/ries/1820

DOI : $10.4000 /$ ries. 1820

ISSN : 2261-4265

Éditeur

France Education international

Édition imprimée

Date de publication : 1 avril 2002

Pagination : 24-25

ISBN : 2-84520-553-8

ISSN : $1254-4590$

Référence électronique

Alain Kimmel, «Olivier Reboul, La Philosophie de l'éducation », Revue internationale d'éducation de Sèvres [En ligne], 29 | avril 2002, mis en ligne le 01 avril 2005, consulté le 05 juillet 2021. URL : http:// journals.openedition.org/ries/1820 ; DOI : https://doi.org/10.4000/ries.1820

Ce document a été généré automatiquement le 5 juillet 2021.

(C) Tous droits réservés 


\section{Olivier Reboul, La Philosophie de l'éducation}

PUF, « Que Sais-Je ? » 9e édition, Paris, 1989, 127 p.

Alain Kimmel

\section{RÉFÉRENCE}

La Philosophie de l'éducation, Olivier Reboul , PUF, « Que Sais-Je ? » 9e édition, Paris, 1989, $127 \mathrm{p}$.

1 Cet ouvrage est la neuvième édition d'un texte paru pour la première fois en 1989. Son auteur, qui est professeur à l'université des sciences humaines de Strasbourg, a publié de nombreux livres consacré à des philosophes qui furent aussi des "éducateurs" (Kant, Nietzsche, Alain) et à des thèmes relatifs à des questions "éducatives " (L'éducation selon Alain, Qu'est-ce qu'apprendre?, Les valeurs de l'éducation...). Il s'attache ici à la "philosophie de l'éducation" qui, pour lui, n'est «pas un corps de savoir, mais une mise en question de tout ce que nous savons ou croyons savoir sur l'éducation». Cette interrogation, qui concerne les fins de l'éducation, est «totale, radicale et vitale ».

2 «Qu'est-ce que l'éducation?» est le titre du premier chapitre du livre. Partant du verbe « éduquer » (educare), il distingue trois synonymes : élever, enseigner, former. Le premier renvoie à la famille, le second à l'école, le troisième tend, depuis quelque temps, à se substituer à la notion d'éducation, qu'il s'agisse de formation initiale, professionnelle, tout au long de la vie... Substitution, mais aussi, souvent, " exclusion », ce que déplore 0 . Reboul qui estime « possible, voire souhaitable, de les unir ».

3 Il examine ensuite la place de l'éducation entre nature et culture (naît-on homme ou le devient-on par l'éducation?), s'interroge sur les fins de l'éducation (éduque-t-on l'enfant pour la société ou pour lui-même?), avant de proposer cette définition: «L'éducation est l'ensemble des processus et des procédés qui permettent à tout enfant 
humain d'accéder progressivement à la culture, l'accès à la culture étant ce qui distingue l'homme de l'animal».

Sont ensuite passées en revue les différentes institutions éducatives : la famille, l'école, l'université. Si la famille a été beaucoup attaquée, l'auteur estime qu'elle est la seule à pouvoir «former les sentiments ». L'école a également été très critiquée, mais le refus radical d'un Ivan Illich, par exemple, montre a contrario, selon 0 . Reboul, ce qu'elle «a d'irremplaçable ». En réponse à l'argumentation d'Illich qui oppose la «syntaxe» de l'école à la "sémantique» de la vie, il distingue cinq caractéristiques du «savoir scolaire : à long terme, organisé, adapté, argumenté, désintéressé ». En revanche, il s'accorde avec le prophète de La société sans école pour dénoncer le "Hors de l'école, point de salut! » et plaider pour le «tiers milieu » éducatif (mouvement de jeunesse, associations, maisons de la culture...). Quant à l'université, elle est toujours confrontée à une série de dilemmes : enseignement de la culture ou formation professionnelle? fonction d'enseignement ou de recherche? sélection ou accès pour tous? ... Pour l'auteur, l'université est essentiellement une institution qui réunit «enseignement supérieur », « recherche fondamentale » et fonctions sociales (« collation des grades et formation des adultes »).

Qui dit éducation dit bien sûr pédagogie, c'est à dire, selon la définition classique, «l'art d'éduquer et d'enseigner ». Mais il y a aussi la théorie de cet art, que Durkheim qualifiait de "théorie pratique». Quelle que soit l'acception que l'on retient, la pédagogie est l'objet de polémiques souvent virulentes. Elles opposent "pédagogues » et " anti-pédagogues». O. Reboul ne veut pas trancher, mais note cependant: « La pédagogie dès qu'elle s'exalte elle-même est toujours tentée de mépriser les savoirs qu'elle est chargée de communiquer. La pente de toute pédagogie est d'être un dogmatisme quant à la forme, la manière d'éduquer, lié à un relativisme quant au contenu ». L'élégance de la formulation n'atténue guère la sévérité de la condamnation. À l'évidence, l'auteur ne se situe pas dans le camp des « pédagogues ", c'est-à-dire ceux qui privilégient la «manière d'enseigner » (la méthode) au détriment du "contenu » (les savoirs). La pédagogie est l'objet d'un mouvement dialectique entre " contrainte » et "désir ", "transmission » et "spontanéité ", "incertitude » et " technicité », " rupture » et "continuité ». Cette série d'« antinomies» ne laisse pas de faire de la pédagogie quelque chose de "profondément idéologique", ainsi que l'attestent les débats passionnés qu'elle ne cesse de susciter en France.

6 «Les valeurs et l'éducation » est le titre du dernier chapitre de cet ouvrage. Le thème est d'importance, mais il a souvent été négligé dans un passé récent et mérite, sans doute, d'être abordé dans une période où les responsables de l'éducation (parents, enseignants, pouvoirs publics...), semblent incertains, voire indifférents quant aux valeurs qu'ils doivent inculquer ou transmettre.

7 Pour Reboul, «il n'y a pas d'éducation sans valeurs ", même si, comme l'affirment certains, toutes les valeurs sont relatives. Ainsi le Bien, le Mal, la Justice, etc. peuvent être diversement appréciés selon les époques, les sociétés, les cultures... Toutefois, « la relativité des valeurs n'abolit pas l'éducation, mais l'universalité de l'éducation ». Il faut se garder, avertit l'auteur, de la confusion entre "relativité » et «relativisme». La première peut être acceptée, le second, pour lui, est, à proscrire.

8 Mais une question demeure: "Comment éduquer selon des valeurs sans endoctriner? » en sachant que le plus grand danger qui menace l'éducation aujourd'hui n'est pas l'endoctrinement idéologique ou religieux - du moins dans les sociétés 
démocratiques - mais l'indifférence ou la démission de tous ceux qui devraient " éduquer ". Reste à déterminer "ce qui vaut la peine d'être enseigné ». À cette interrogation, Reboul répond : « Ce qui unit et ce qui libère ».

9 En guise de conclusion à son étude, O. Reboul souligne qu'elle devrait avoir pour titre "Une philosophie de l'éducation » et non "La philosophie de l'éducation », mais que, pour lui, la philosophie humaniste qu'il développe est la seule. On peut certes contester une telle affirmation, voire la réfuter. Force est cependant de reconnaître que ce petit livre foisonnant a le grand mérite de poser de bonnes questions et d'y apporter des réponses certes personnelles, mais souvent justes et toujours d'une grande honnêteté et d'une grande clarté.

\section{AUTEURS}

\section{ALAIN KIMMEL}

Chargé de programmes, CIEP 